\title{
World Bank calls for a fairer deal on patents and knowledge
}

[PARIS] Developing countries which are unhappy with new international treaties tightening intellectual property rights (IPR) received unexpected support this week from the bastion of capitalism, the World Bank.

In Knowledge for Development, the 21st report in the bank's annual series on world development, the bank argues that stronger international IPR legislation risks "shifting bargaining power towards the producers of knowledge, and increasing the knowledge gap" between industrialized and developing countries. It called on developing countries to take a more proactive and hardline stance in international IPR negotiations.

Traditionally the World Bank, established at a meeting of world leaders in 1944 as part of efforts to reconstruct the world economy after the Second World War, has focused largely on promoting economic development, for example through increased free trade. The new report identifies "knowledge" as a less tangible, but central, factor for improving health and living standards.

"Knowledge can make the difference between sickness and health, between poverty and wealth," Lyn Squire, director of development economics at the bank, told a press briefing in Paris last week. Internet access alone will have a revolutionary impact on Third World development, Squire predicted. And the report warns that the vertiginous growth in global knowledge creates the risk that poor countries may fall further behind.
The 1994 agreement on trade-related aspects of intellectual property rights (TRIPS) has created a global regime which sets minimum standards for IPR protection. It also sets, for the first time, an international legal mechanism, through the World Trade Organization's dispute settlement procedure, to sanction countries which fail to abide by the legislation.

The report points out the need to strike a balance between providing incentives for generating new knowledge, and creating conditions for its dissemination. A bank study of drug and chemical companies in the United States, Germany and Japan found that more than a quarter felt that IPR protection in developing countries including China, India and Argentina was too weak to allow investment or technology transfer.

But it warns that there is now a risk of excessively strict IPR adversely affecting follow-on innovations that draw on patents, and actually slowing the pace. Of particular concern is the current tendency for patents to cover not just products but broad areas of technology, in particular in biotechnology.

"So many industrial-country firms are acquiring strong IPR positions, often covering fundamental research tools as well as marketable products, that it may prove hard for new firms and researchers to elbow into this new global industry," says the report.

Furthermore, the report argues that IPR is not an appropriate mechanism to stimu-

\section{Magnetar blasts its way out of theory}

[WASHINGTON] An enormous blast of gammarays and $\mathrm{X}$-rays from a distant star arrived at Earth on the night of 27 August, giving scientists their best evidence yet for a 'magnetar'-a neutron star with a magnetic field stronger than any other known object in the Universe (see right). The event temporarily overloaded X-ray detectors on several spacecraft.

Several teams reported their observations of the event at a press conference at the US space agency NASA last week. The flash came from the Soft Gamma Repeater known as SGR 1900+14, which lies 20,000 light years away in the constellation known as Aquila.

At least seven spacecraft, including the NEAR asteroid probe near the orbit of Mars and the Ulysses solar probe just inside Jupiter's orbit, registered the passing wave.

Although magnetars have been the subject of theory since 1992, the first one

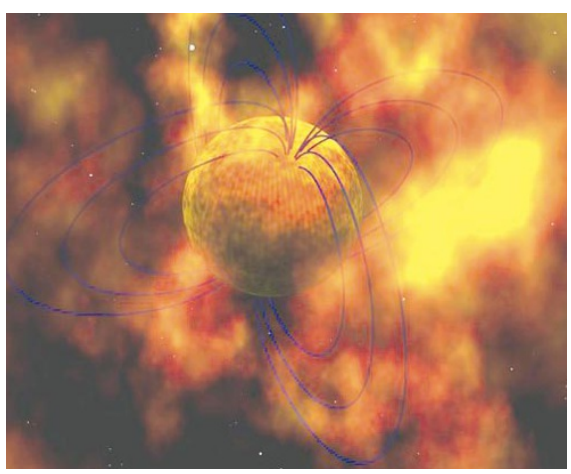

Disruptive influence: an artist's impression of a magnetar, with magnetic field lines shown in blue.

was not identified until recently (see Nature $393,235 ; 1998)$. Their intense magnetic fields -800 trillion times the strength of Earth's - cause the star's thin, solid crust to ripple and crack, occasionally releasing great bursts of energy. Tony Reichhardt

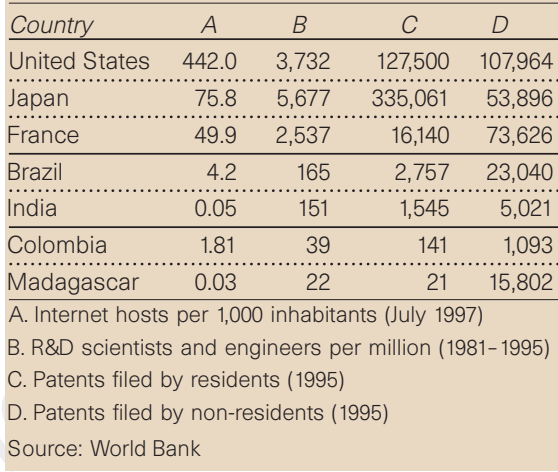

Worlds apart: gap between richest and poorest is growing in terms of access to knowledge.

late research in many areas of health and medicine, such as AIDS or malaria, where, as it points out, the "social returns" of an innovation - to all those benefiting from it - far exceed the returns to investors. Here, it says, public authorities have a responsibility to subsidize research or provide financial incentives to the private sector, as recently proposed for development of antimalarial drugs (see Nature 395, 417-8; 1998).

At the same time, the bank points out that such concerns need to be balanced against the advantages of stricter IPR. These include greater access to foreign markets and technology for countries which enforce international IPR standards, compared with those whose lack of legislation deters investors.

The report proposes no solutions, but calls on developing countries "to negotiate internationally for intellectual property right regimes that give adequate consideration to their urgent need to narrow the knowledge gap", while maintaining incentives for knowledge producers to invest in research. They should also keep up to speed on "new issues for negotiation, such as biotechnology and information technology".

In a bid to practice what it preaches, the bank — which agreed to loans of $\$ 28,594$ billion in 1998 compared with $\$ 19,147$ billion last year, has now set itself the objective of becoming a clearing house for information on development. It plans to make its vast inhouse expertise and archives, such as staff reports on various developmental issues, available on the Internet by 2000 .

Developing countries need to be assertive in defending the terms under which companies are given access to their resources, says the report. In 1990, world sales of medicines derived from plants discovered by indigenous peoples amounted to $\$ 43$ billion, with hardly any financial return to these groups (see Nature 392, 535-540; 1998).DeclanButler 